\title{
Intensive treatment of hyperglycemia in the acute phase of myocardial infarction: the tenuous balance between effectiveness and safety - a systematic review and meta-analysis of randomized clinical trials
}

\author{
Paulo H. Negreiros ${ }^{*}$ \\ (iD) Adriana Bau" ${ }^{*}$ \\ (iD) Wilson Nadruz' \\ (iD) Otavio R. Coelho-Filho' \\ (iD) José Roberto Matos-Souza ${ }^{1}$ \\ (iD) Otavio R. Coelho' \\ (iD) Andrei C. Sposito ${ }^{1}$ \\ (iD) Luiz Sergio F. Carvalho'
}

*The co-authors had an equal contribution for this present article.
1. Cardiology Department, Faculty of Medical Sciences, State University of Campinas (Unicamp), Campinas, SP, Brasil

http://dx.doi.org/10.1590/1806-9282.65.1.24

\section{SUMMARY}

INTRODUCTION: In acute myocardial infarction (AMI), each $18 \mathrm{mg} / \mathrm{dl}(1 \mathrm{mmol} / \mathrm{L})$ increment is associated with a $3 \%$ increase in mortality rates. All strategies applied for reducing blood glucose to this date, however, have not presented encouraging results.

METHODOLOGY: We searched the Medline (PubMed) and Cochrane Library databases for randomized clinical trials (RCTs) from 1995 to 2017 that used the intensive strategy or GIK therapy for blood glucose control during the acute stage of the AMI. We included eight studies. In order to identify the effects of GIK or insulin therapy, we calculated a overall risk ratio (RR) with meta-analysis of fixed and random effects models. A two-tail p-value of $<0.05$ was considered statistically significant.

RESULTS: A total of 28,151 patients were included: 1,379 intensively treated with insulin, 13,031 in GIK group, and 13,741 in the control group. The total mortality was $10.5 \%(n=2,961)$ and the RR of $1.03[95 \% \mathrm{Cl} 0.96-1.10] ; 12=31 \% ; p=0.41$ for the combined intensive insulin plus GIK groups in comparison with the control group. In meta-regression analyses, intense reductions in blood glucose (> 36 $\mathrm{mg} / \mathrm{dL}$ ) in relation to the estimated average blood glucose (estimated by $\mathrm{HbA1c}$ ) were associated with higher mortality, whereas lower reductions in blood glucose $(<36 \mathrm{mg} / \mathrm{dL}$ ) were not associated with mortality. The lowering of blood glucose in the acute phase of $\mathrm{Ml}$ compared with the average blood glucose was more effective around $18 \mathrm{mg} / \mathrm{dL}$.

CONCLUSION: This meta-analysis suggests that there may be a tenuous line between the effectiveness and safety of reducing blood glucose in the acute phase of MI. The targets must not exceed a reduction greater than $36 \mathrm{mg} / \mathrm{dL}$ in relation to estimated average blood glucose.

KEYWORDS: Hyperglycemia. Myocardial infarction. Meta-analysis as the subject. Effectiveness. Safety. Critical care.

DATE OF SUBMISSION: 12-Oct-2018

DATE OF ACCEPTANCE: 26-Oct-2018

CORRESPONDING AUTHOR: Luiz Sérgio F de Carvalho

Cardiology Department - Faculty of Medical Sciences - State University of Campinas (Unicamp)

13084-971, Campinas, São Paulo, Brasil

E-mail: luizsergiofc@gmail.com 


\section{INTRODUCTION}

Stress hyperglycemia is a powerful prognostic marker for acute myocardial infarction (AMI), ${ }^{\mathbf{1}}$. It represents not only a consequence of inflammatory activation, adrenergic and endocrine but also contributes to the continuation of these phenomena. In AMI patients, each $18 \mathrm{mg} / \mathrm{dl}(1 \mathrm{mmol} / \mathrm{L})$ increment is associated with a $3 \%$ increase in mortality due to all causes ${ }^{1 .}$ In a different study, each increment of capillary blood glucose over $140 \mathrm{mg} / \mathrm{dl}$ was translated as a directly proportional increase in the mortality of these patients over five years ${ }^{2}$.

Overall, however, all strategies applied for reducing blood glucose to this date have not presented encouraging results. As the first strategy for the intensive control of blood glucose, the Digami- $1^{3}$ presented an aggressive reduction in the blood glucose of diabetic patients with AMI was associated with a decrease in mortality. However, these findings could not be reproduced by subsequent studies - both Digami- $2^{4}$ and HI- $5^{5}$ failed to demonstrate the benefits of using the intensive treatment for blood glucose during an acute coronary event. Randomized studies with the same purpose of comparing a more rigorous treatment for stress hyperglycemia with more conservative methods, in the context of other critical conditions, also failed, like the multicenter Nice-Sug$\mathrm{ar}^{6}$. This study suggested a $14 \%$ increase in patient mortality with the intensive control of hyperglycemia, overall, due to an increase in the risk of hypoglycemia.

The concept of metabolic modulation in the acute stage of AMI with the purpose of promoting electrical stability in the myocardium after an ischemic event started in 1960 with the glucose-insulin-potassium therapy $(\mathrm{GIK})^{7}$. However, there is an extremely tenuous balance between the plasma glucose and insulin resistance in the ischemic myocardium, in which, on the one hand, there is a necessity for high blood glucose levels in order to defeat the cellular mechanisms for insulin resistance and, on the other hand, a relative insulin deficiency in the acute stage. The mere provision of glucose and insulin could facilitate the glucose uptake by the myocardium, provided that in balance with the glucose consumption rate. If that balance is broken, the deleterious effect of hypoglycemia or hyperglycemia will prevail.

In studies such as Digami I and II, Gips I $^{8}$ and II $^{9}$, Create-Ecla ${ }^{10}$, and other trials, the diametrically opposite impacts on cardiovascular mortality due to all causes were not revealed. Although the proportion of hypoglycemia partially explains these findings, there is no clear explanation for such divergent results. In order to answer that question, we propose a meta-analysis followed by meta-regression using data published from trials on the intensive control of blood glucose in the acute stage of AMI.

\section{METHODS}

A detailed description of all the procedures is included in the Supplementary Data (from the Data Source and Research section to the Studies Included and Excluded). In short, the Medline (PubMed), Cochrane Library and ClinicalTrials.gov databases were searched for original articles from 1995 to 2017 in order to identify all randomized clinical trials (RCTs) that used an intensive strategy or GIK therapy for the control of blood glucose levels during the acute stage of AMI. Original essays were considered eligible for the present meta-analysis if they met the following criteria: 1) Phase 2 or 3 RCT; 2) participants of the AMI acute event; 3) the participants of the treatment group used insulin or GIK therapy during the study. We excluded the studies that, despite being related to this subject, did not present mortality data or a comparison between a more intensive strategy for the control of stress hyperglycemia with more conservative strategies, or that presented biases in the randomization or data analysis. Two researchers analyzed the data using pre-set forms and independently assessed the precision of the analysis, resolving any discrepancies through a consensus after a discussion with the third researcher. The baseline data were obtained through weighted calculation. In order to identify the potential effects of GIK or insulin therapy in the AMI, we calculated an overall risk ratio (RR) with meta-analysis of fixed and random effects models. Odds Ratios and risk ratios were universally identical during the data analysis. More details on the data analysis can be found in Annex 1 (Data Analysis and Synthesis). For the estimate of the effects of the resumed treatment, a two-tail p-value of $<0.05$ was considered statistically significant. We used Stata 13 to analyze the data.

\section{RESULTS}

In total, we identified over 20 studies on the control of hyperglycemia in events of acute myocardial 
infarction, out of which nine were included in our study (Table 1). All other studies were not included in our meta-analysis because they did not present assessments of the polarity of more intensive or conservative approaches.

With that in mind, the studies analyzed were conducted between the years of 1995 and 2007 and all were clinical trials with a multicenter and randomized design. The average of follow-up for all the studies was of 11.5 months; Digami- 1 was the one with the longest patient follow-up time (40.8 months), while all the others (except for Digami-2, which followed-up with the patients for 36 months) had a follow-up time between one and six months. In total, there were 28,151 patients included; of these, 1,379 were included in the group for intensive capillary blood glucose treatment, while 13,031 were in the group for GIK treatment, and 13,741 in the control group (734 in the studies that were compared with the intensive strategy, and 13,007 in the studies that assessed the use of GIK). In total, about $34.7 \%$ of patients were female, with an average age of 62.6 years.
After dividing the sample between the studies that sought blood glucose levels with an emphasis on a more intensive regimen of insulin in the acute stage of infarction, we had 2,113 patients in the intensive treatment group, and 734 in the control group, with $39 \%$ of patients being female, with an average age of 66.1 years. In this subgroup, the average pre-randomized blood glucose of patients was of $234.72 \mathrm{mg} /$ $\mathrm{dl}$, with a $7.45 \%$ mean value for glycated hemoglobin (HbA1C) for these patients. After separating the patients into the intensive and conservative treatment groups, for the first group, the average blood glucose value was of $148.68 \mathrm{mg} / \mathrm{dl}$, while on the latter it was of $159.48 \mathrm{mg} / \mathrm{dl}$, with post-follow-up HbA1C values of $7.06 \%$ and $7.1 \%$, respectively.

As for the studies that assessed the use of the glucose-insulin-potassium therapy solution, there was a total of 26,038 patients, with 13,031 in the GIK group and 13,007 in the conservative treatment group. There was an average of $32.6 \%$ female patients, with an average age of 60.9 years. The average pre-randomized blood glucose was of $150.48 \mathrm{mg} / \mathrm{dl}$ between the sub-

TABLE 1 - DESCRIPTIVE ANALYSIS OF THE STUDIES ANALYZED

\begin{tabular}{|c|c|c|c|c|c|c|c|c|c|}
\hline Trial & Digami & Digami 2 & $\mathrm{HI}-5$ & Gips I & Oasis 6 & $\begin{array}{l}\text { Cre- } \\
\text { ate-Ecla } \\
\text { trial }\end{array}$ & $\begin{array}{l}\text { Pache } \\
\text { et al }\end{array}$ & Gips II & Pol-GIK \\
\hline Year & 1995 & 2005 & 2006 & 2003 & 2007 & 2005 & 2004 & 2006 & 1999 \\
\hline Design & RCT & RCT & RCT & RCT & RCT & RCT & RCT & RCT & RCT \\
\hline Follow-up (months) & 40.8 & 36 & 6 & 1 & 6 & 1 & 6 & 1 & 6 \\
\hline Female (\%) & 62.5 & 33 & 21.6 & 60.1 & 27.6 & 22.4 & 27.9 & 26.4 & 31.4 \\
\hline $\begin{array}{l}\text { Average pre-randomized age } \\
\text { (years) }\end{array}$ & 67.5 & 68.3 & 62.6 & 60.3 & 61.8 & 58.6 & 62.4 & 61.5 & 61.0 \\
\hline Pre-randomized DM II (\%) & 100 & 100 & 48.3 & & 14.5 & 17.7 & 23.1 & 9.5 & 6.3 \\
\hline DM II in insulin use (\%) & 34.6 & 31.1 & 7.9 & & & & & 2.5 & 1.9 \\
\hline Heart failure (\%) & 21.9 & 23.9 & & 8.2 & 13.5 & 1.65 & & & 7.7 \\
\hline Undiagnosed DM II (\%) & 12.5 & & & & & & & & \\
\hline Pre-randomized HbA1C (\%) & 8.1 & 7.26 & 7.0 & & & & & & \\
\hline $\begin{array}{l}\text { Pre-randomized blood glucose } \\
(\mathrm{mg} / \mathrm{dl})\end{array}$ & 279 & 229.1 & 196.2 & 153 & 160.2 & 162 & & 153 & 124.2 \\
\hline Intensive treatment sample & 306 & 947 & 126 & & & & & & \\
\hline Conservative treatment sample & 314 & 306 & 114 & 464 & 1,374 & 10,107 & 157 & 445 & 460 \\
\hline GIK sample & & & & 476 & 1,374 & 10,088 & 155 & 444 & 494 \\
\hline $\begin{array}{l}\text { Post-intensive treatment blood } \\
\text { glucose }(\mathrm{mg} / \mathrm{dl})\end{array}$ & 210.6 & 163.8 & 144 & & & & & & \\
\hline $\begin{array}{l}\text { Post-conservative treatment } \\
\text { blood glucose }(\mathrm{mg} / \mathrm{dl})\end{array}$ & 172.8 & 180 & 145.8 & 145.8 & 133.2 & 135 & & & 111.6 \\
\hline Post-GIK blood glucose (mg/dl) & & & & 138.6 & 151.2 & 154.8 & & & 106.2 \\
\hline $\begin{array}{l}\text { Post-intensive treatment } \mathrm{HbA} 1 \mathrm{C} \\
(\%)\end{array}$ & 7.0 & 6.8 & 7.4 & & & & & & \\
\hline $\begin{array}{l}\text { Post-conservative treatment } \\
\mathrm{HbA} 1 \mathrm{C}(\%)\end{array}$ & 7.5 & 6.8 & 7.0 & & & & & & \\
\hline
\end{tabular}

RCT - Randomized Clinical Trial; DM II - Type II Diabetes Mellitus; GIK - glucose-insulin-potassium solution; HbA1C - Glycated Hemoglobin. 


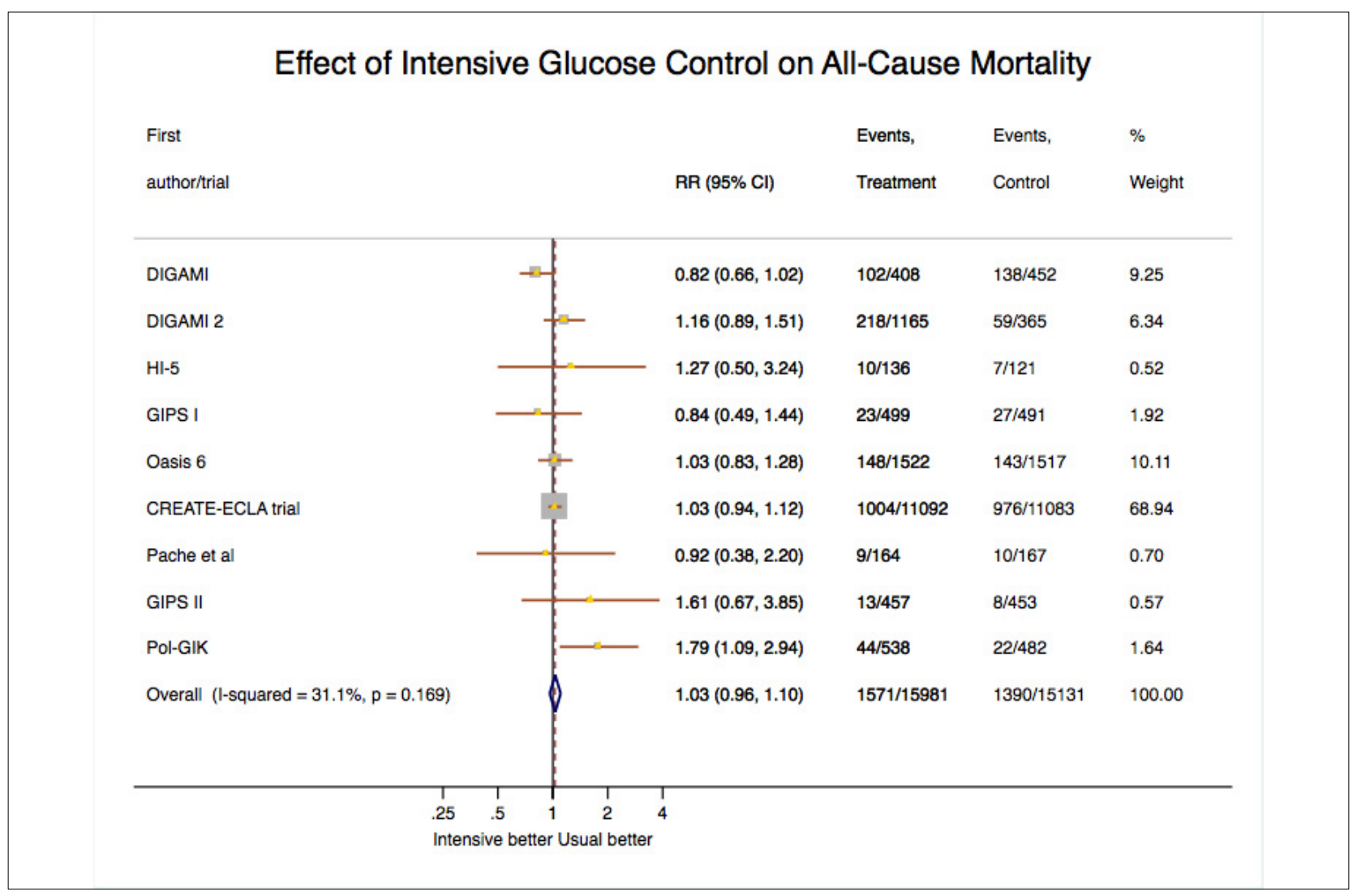

FIGURE 1

groups, with $131.4 \mathrm{mg} / \mathrm{dl}$ for patients of the conservative treatment and $137.7 \mathrm{mg} / \mathrm{dl}$ in the GIK group.

The mortality rates for all causes are described in Figure 1. The grouped data show that the total mortality of the studies included was of 2,961 (10.5\%). When once again divided into subgroups, there were 330 in the group for intensive control of capillary blood glucose, against 204 in the group for the conservative treatment (15.6\% against 9.6\%, respectively). Among the patients assessed for the GIK treatment, the total mortality was of 1,186 individuals (4.7\%) for patients who used this strategy, against 1,186 patients of the conservative treatment (4.5\%). Thus, the risk ratio for mortality due to all causes was of 1.03 [95\% CI 0.961.10]; $\mathrm{I}^{2}=31 \% ; \mathrm{p}=0.41$ ). As shown in Supplementary Figure 1, there was no significant publication bias in the funnel charts and no significant bias concerning small studies, according to the Egger tests $(p=0.57)$.

Finally, with the purpose of finding possible explanations for the discrepant findings between the trials, we conducted a series of meta-regressions (Supplementary Figures 2 and 3). As shown in figure 2 , we can see that abrupt and intense reductions in blood glucose in relation to the average estimated blood glucose (> $2 \mathrm{mmol} / \mathrm{L}$ or $>35 \mathrm{mg} / \mathrm{dL}$ ) were asso- ciated with a higher risk of death, while reductions with low intensity (around zero) were not significantly associated with an increment or reduction in mortality due to all causes. Contrastingly, the lowering of blood glucose in the acute stage compared with the average blood glucose was more effective around 1 $\mathrm{mmol} / \mathrm{L} 18 \mathrm{mg} / \mathrm{dL}$ ( $\mathrm{p}=0.008$ for the tendency in the restricted cubic spline).

\section{DISCUSSION}

The present systematic review assessed the impact of the intensive control of blood glucose levels in the acute stage of AMI, following different strategies, over the mortality due to all causes. A raw analysis of the impact of intensive control suggests there is no difference in comparison with the usual control. However, we have shown there is a fine limit between the magnitude of the fasting glucose reduction in relation with the average blood glucose levels before the AMI (based on the glycated hemoglobin) and the results of the intensive blood glucose control approach. In this context, intense and abrupt reductions of blood glucose ( $>2 \mathrm{mmol} / \mathrm{L}$ or $>35 \mathrm{mg} /$ $\mathrm{dL}$ ) seem to lead to a higher risk of death, while re- 


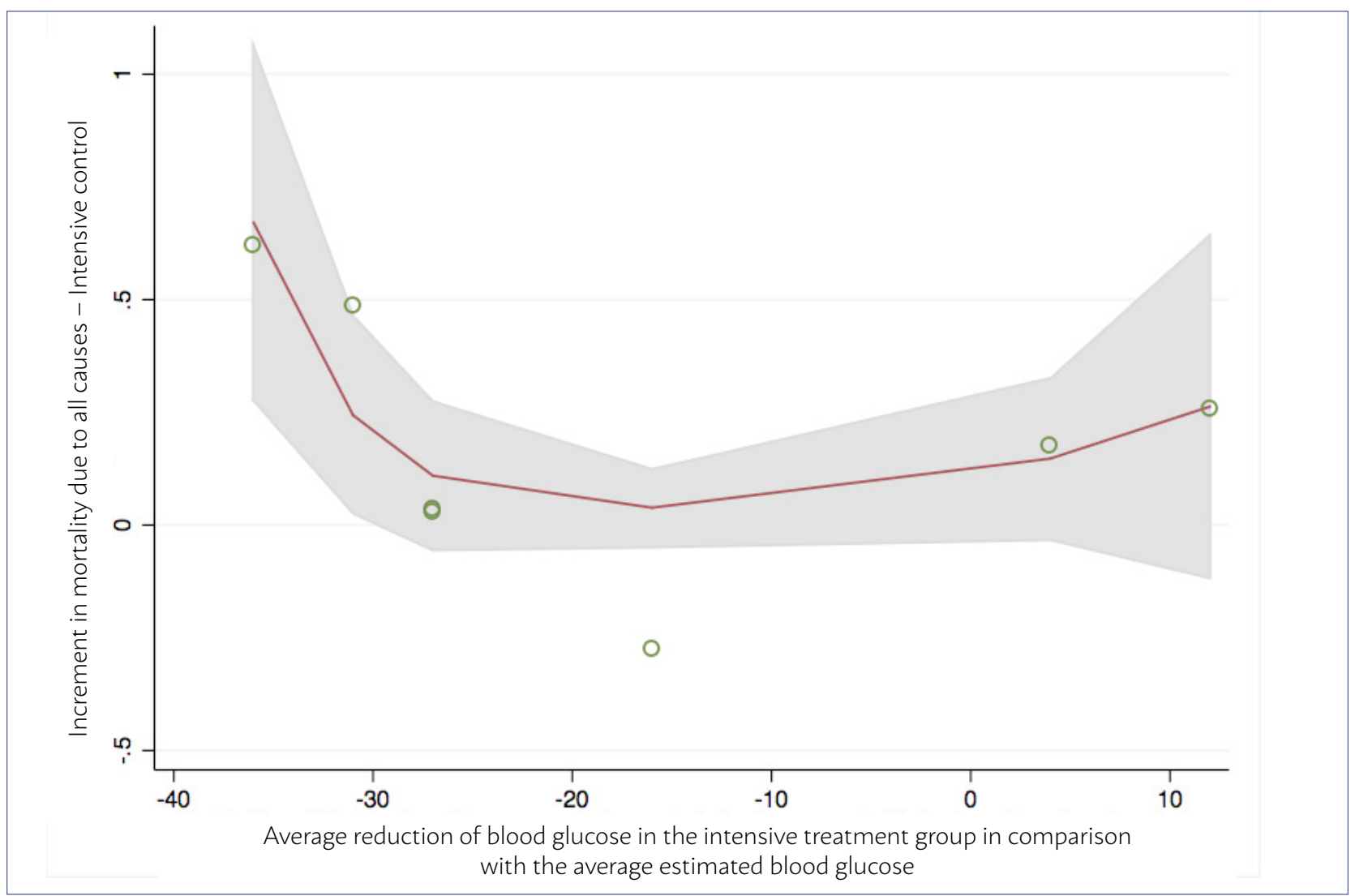

FIGURE 2

ductions with low intensity (around zero) seem not to influence death risk. On the other hand, a reduction of around $1 \mathrm{mmol} / \mathrm{L}$ (or $18 \mathrm{mg} / \mathrm{dL}$ ) of the blood glucose during the acute stage compared with the estimated average seems to be the most secure and effective strategy to reduce the risk of death due to all causes in the context of AMI.

Stress hyperglycemia is common in the context of critically ill patients ${ }^{6}$ and is not different from the acute stage of the acute myocardial infarction ${ }^{1,2,11,12}$. It is a powerful risk marker since it reflects the systemic and sympathetic activity and plasma levels of catecholamines, cortisol, and glucagon after the ischemic event ${ }^{13}$. When it is present at the AMI patient's admission into hospital, it is related with higher mortality rates, worse outcomes in primary angioplasty and an increase in the number of Timi 0 flows in coronary angiographies, as well as a more significant development of heart failure and cardiogenic shock. The pathophysiology is still little known; however, it is known that the hyperglycemia is associated with endothelial dysfunction in the context of acute AMI ${ }^{15}$.

The cells of the vascular endothelium play an essential part in cardiovascular homeostasis, secreting a series of mediators that regulate the platelet aggregation, coagulation, and vascular tonus ${ }^{16}$. The term "endothelial dysfunction" refers to a condition in which the endothelium loses its physiological properties, with a tendency of promoting arteriolar vasodilation, fibrinolysis, and anti-aggregation. The mediators secreted by these cells can perform both vasoconstriction, through endothelin-1 and thromboxane A2, and vasodilation through nitric oxide and prostacyclin. In patients with hyperglycemia and diabetes, there is a deficiency in the production of nitric oxide, which causes a vascular imbalance towards vasoconstriction ${ }^{16}$.

It is also known that., in physiological conditions, the myocardium metabolizes, preferably, free fatty acids; however, in ischemic conditions, it uses glucose in a relatively higher proportion. Nevertheless, the insulin resistance developed during the AMI acute stage generates an immediate limiting factor to the absorption of the energy substrate, which can contribute to the worsening of the myocardium injury. Thus, both endothelial dysfunction caused by hyperglycemia and insulin resistance can explain the adverse outcomes of exacerbated hyperglycemia in the second acute stage of AMI ${ }^{1,11}$.

After these conclusions, the question was what 
would be the ideal blood glucose target after the AMI, since, for the reasons previously mentioned, even patients who did not have diabetes were hyperglycemic upon the admission of the ischemic event. Thus, was born the 1995 Digami $^{3}$ study, which set out to study 620 patients grouped into a more permissive hyperglycemic approach and a more intensive approach for the control of blood glucose levels through the use of a glucose-insulin solution. They were, initially, encouraging of an intensive strategy, since after a 40.8 months follow-up there was a reduction of $11 \%$ of mortality in the intensive group, which was more evident in the low-risk groups who were not previously treated with insulin therapy.

The following studies then - Digami- $2^{4}$ e HI- $5^{5}$ - tried to reproduce a similar design to the Digami but were not very successful. In the first one, there was no difference in mortality between the groups, possibly due to the excellent blood glucose levels on both. In the HI-5, the absence of significant differences in mortality could be explained by the reduced number of patients in a study that, perhaps, was not adequately blinded.

When we analyze the results of these three studies (Digami, Digami-2 e HI-5), we can see that the post-intensive treatment blood glucose level was of $172.8 \mathrm{mg} / \mathrm{dl}, 163.8 \mathrm{mg} / \mathrm{dl}$, and $144 \mathrm{mg} / \mathrm{dl}$, respectively, while in the groups randomized for the conservative treatment it was $210.6 \mathrm{mg} / \mathrm{dl}, 180 \mathrm{mg} / \mathrm{dl}$, and $145.8 \mathrm{mg} / \mathrm{dl}$; the average for HbA1c was $8.1 \%, 7.23 \%$, and $7 \%$, also respectively. The Digami data show that this study had the highest values for blood glucose in both groups in comparison with the other two studies, while the HI-5 was the one with the lowest values. This analysis suggests that higher blood glucose values might be related to better outcomes when compared with lower values in more intensive approaches. Accordingly, the meta-regression results suggested there is a tenuous line between effectiveness and safety for the reduction of blood glucose in the acute stage.

The studies on GIK therapy were motivated by the theoretical benefits of the solution in increasing the availability of glucose and potassium to the myocardium associated with the insulin effect that facilitates the glucose oxidation, reduces circulating fatty acids, thus improving the parameters for coagulation and the anti-inflammatory effects, and reducing arrhythmias and changes in contractility. The studies included in this meta-analysis assessed 13,031 pa- tients who underwent GIK therapy and 13,007 who underwent the conventional treatment; Create-Ecla ${ }^{10}$ had the largest sample, with 20,201 patients.

The Gips- $\mathrm{I}^{8}$ study compared the GIK therapy infusion or placebo in 940 AMI patients eligible for primary angioplasty in 8-12 hours, showing clinical benefits for the patients, with no signs of heart failure; however, the following study, Gips-II ${ }^{9}$, could not confirm this finding.

Similarly, in the most recent Create-Ecla, a study that assessed the effects of a high dose of GIK did not present a significant difference in mortality. The Oasis- $6^{17}$ study was prematurely interrupted after 2,748 patients were enrolled after the publication of the Create-Ecla; the Oasis-6 showed no benefits to the GIK treatment.

Despite that, a recent analysis of the Oasis- 6 and Create-Ecla studies combined the populations of both, showing an increase in mortality for the treatment with GIK, especially over the first three days.

In a meta-analysis published in 1997 by Fath-Ordoubadi \& Beatt ${ }^{18}$ and reviewed by Mamas et al. ${ }^{19}$ in 2010, it was demonstrated that the GIK therapy in the studies analyzed conducted during a pre-revascularization/fibrinolysis period presented benefits for the clinical outcome. Upon comparing these data with more recent studies, it is possible that the GIK therapy benefits only patients in whom the reperfusion has not been reached.

When analyzing the studies, it is evident that the interventions by the GIK studies, overall, provided better blood glucose control for patients in both groups. For those submitted to GIK therapy, there was a discrete increase in blood glucose in comparison with the placebo group, whose average pre-randomization blood glucose was of 150.48. After the intervention, the blood glucose average in the treatment group was of 137.7, and the average in the placebo group was 131.4. Both results were very similar, which might justify the absence of benefits for the reduction of mortality when both groups were compared.

\section{CONCLUSION}

Few reported studies assess blood glucose control guided by goals in an intensive environment and that included acute coronary syndrome patients. The present meta-analysis demonstrated that the data on the interval between blood glucose levels that 
should be sought during the acute stage of the AMI is inconsistent and that GIK therapy did not present any benefits for this same group of patients. On the other hand, our study supports the hypothesis that there must be a fine limit between effectiveness and safety for blood glucose reduction in the acute stage.
Thus, the reasonable blood glucose targets should be guided, preferably, by the average estimated blood glucose and should not exceed a reduction of $36 \mathrm{mg} /$ dL of blood glucose. Additional studies are still necessary to confirm the ideal targets and dissect the differences between diabetic and non-diabetic patients.

\section{RESUMO}

INTRODUÇÃo: No infarto agudo do miocárdio (IAM), cada incremento de $18 \mathrm{mg} / \mathrm{dl}$ ( $1 \mathrm{mmol} / \mathrm{L})$ se associa a um aumento de $3 \%$ na mortalidade. As estratégias de redução da glicemia tentadas até o momento, entretanto, não trouxeram resultados animadores.

METODOLOGIA: Foram pesquisadas nas bases de dados Medline (PubMed) e Cochrane Library os ensaios clínicos randomizados (ECRs) de 1995 a 2017 que utilizaram estratégia intensiva ou a terapia GIK no controle glicêmico durante a fase aguda do IAM. Foram incluídos oito estudos. Para identificar os efeitos da insulinoterapia ou da terapia GIK, calculamos um risco relativo geral (RR) com meta-análises de modelos de efeitos fixos e aleatórios. Um valor de p-bicaudal < 0,05 foi considerado estatisticamente significativo.

RESULTADOS: Foram incluídos 28.151 pacientes, sendo 1.379 no grupo de tratamento intensivo da glicemia, 13.031 no GIK e 13.741 no controle. A mortalidade total foi de 2.961 (10,5\%), computando um risco relativo de 1,03 [95\% Cl 0,96-1,10]; $l^{2}=31 \% ; p=0,41$ para o grupo intensivo ou GIK contra o grupo conservador. Reduções intensas (> $36 \mathrm{mg} / \mathrm{dL}$ ) em relação à glicemia estimada média se associaram à maior mortalidade, enquanto reduções menores não se associaram com seu incremento ou redução. A redução glicêmica na fase aguda em relação à glicemia estimada média foi mais efetiva e segura na faixa em torno de $18 \mathrm{mg} / \mathrm{dL}$.

CONCLUSÃO: Esta meta-análise levanta a hipótese de haver um limite tênue entre efetividade e segurança para a redução glicêmica na fase aguda, sendo que os alvos não devem exceder uma redução maior do que $36 \mathrm{mg} / \mathrm{dL}$ de glicemia.

PALAVRAS-CHAVE: Hiperglicemia. Infarto do miocárdio. Meta-análise como assunto. Efetividade. Segurança. Cuidados críticos.

\section{REFERENCES}

1. Stranders I, Diamant M, van Gelder RE, Spruijt HJ, Twisk JW, Heine RJ, et al. Admission blood glucose level as risk indicator of death after myocardial infarction in patients with and without diabetes mellitus. Arch Intern Med. 2004;164(9):982-8.

2. Mulder M, Cornel JH, van der Ploeg T, Boersma E, Umans VA. Elevated admission glucose is associated with increased long-term mortality in myocardial infarction patients, irrespective of the initially applied reperfusion strategy. Am Heart J. 2010;160(3):412-9.

3. Malmberg K, Rydén L, Efendic S, Herlitz I, Nicol P, Waldenström A, et al. Randomized trial of insulin-glucose infusion followed by subcutaneous insulin treatment in diabetic patients with acute myocardial infarction (DIGAMI study): effects on mortality at 1 year. J Am Coll Cardiol. 1995;26(1):57-65.

4. Malmberg K, Rydén L, Wedel H, Birkeland K, Bootsma A, Dickstein K, et al. DIGAMI 2 Investigators. Intense metabolic control by means of insulin in patients with diabetes mellitus and acute myocardial infarction (DIGAMI 2): effects on mortality and morbidity. Eur Heart J. 2005;26(7):650-61.

5. Cheung NW, Wong WW, McLean M. The hyperglycemia: intensive insulin infusion in infarction (HI-5) study: a randomized controlled trial of insulin infusion therapy for myocardial infarction. Diabetes Care. 2006;29(4):765-70.

6. Inzucchi SE, Siegel MD. Glucose control in the ICU: how tight is too tight? N Engl J Med. 2009;360(13):1346-9.

7. Sodi-Pallares D, Testelli MR, Fishleder BL, Bisteni A, Medrano GA, Friedland $C$, et al. Effects of an intravenous infusion of a potassium-glucose-insulin solution on the electrocardiographic signs of myocardial infarction. A preliminary clinical report. Am J Cardiol. 1962;9:166-81.

8. Van der Horst IC, Zijlstra F, van't Hof AW, Doggen Cl, de Boer MI, Suryapranata H, et al.; Zwolle Infarct Study Group. Glucose-insulin-potassium infusion in patients treated with primary angioplasty for acute myocardial infarction: the glucose-insulin-potassium study: a randomized trial. J Am Coll Cardiol. 2003;42(5):784-91.

9. Timmer $\mid R$, Svilaas $T$, Ottervanger $J P$, Henriques $J P$, Dambrink $J H$, van den Broek SA, et al. Glucose-insulin-potassium infusion in patients with acute myocardial infarction without signs of heart failure: the Glucose-Insulin-Potassium Study (GIPS)-II. J Am Coll Cardiol. 2006;47(8):1730-1.
10. Mehta SR, Yusuf S, Diaz R, Zhu J, Pais P, Xavier D, et al.; CREATE-ECLA Trial Group Investigators. Effect of glucose-insulin-potassium infusion on mortality in patients with acute ST-segment elevation myocardial infarction: the CREATE-ECLA randomized controlled trial. JAMA. 2005;293(4):437-46.

11. Kosiborod M, Rathore SS, Inzucchi SE, Masoudi FA, Wang Y, Havranek EP, et al. Admission glucose and mortality in elderly patients hospitalized with acute myocardial infarction: implications for patients with and without recognized diabetes. Circulation. 2005;111(23):3078-86.

12. Goyal A, Mahaffey KW, Garg J, Nicolau JC, Hochman JS, Weaver WD, et al. Prognostic significance of the change in glucose level in the first $24 \mathrm{~h}$ after acute myocardial infarction: results from the CARDINAL study. Eur Heart J. 2006;27(11):1289-97.

13. Oswald GA, Smith CC, Betteridge DJ, Yudkin IS. Determinants and importance of stress hyperglycaemia in non-diabetic patients with myocardial infarction. Br Med J. 1986;293(6552):917-22.

14. Capes SE, Hunt D, Malmberg K, Gerstein HC. Stress hyperglycaemia and increased risk of death after myocardial infarction in patients with and without diabetes: a systematic overview. Lancet. 2000; 355(9206):773-8.

15. Chen SM, Tsai TH, Hang CL, Yip HK, Fang CY, Wu Cl, et al. Endothelial dysfunction in young patients with acute ST-elevation myocardial infarction. Heart Vessels. 2011;26(1):2-9.

16. Fadini GP, Sartore S, Agostini C, Avogaro A. Significance of endothelial progenitor cells in subjects with diabetes. Diabetes Care. 2007;30(5):130513.

17. Díaz R, Goyal A, Mehta SR, Afzal R, Xavier D, Pais P, et al. Glucose-insulin-potassium therapy in patients with ST-segment elevation myocardial infarction. JAMA. 2007;298(20):2399-405.

18. Fath-Ordoubadi F, Beatt KJ. Glucose-insulin-potassium therapy for treatment of acute myocardial infarction: an overview of randomized placebo-controlled trials. Circulation. 1997;96(4):1152-6.

19. Mamas MA, Neyses L, Fath-Ordoubadi F. A meta-analysis of glucose-insulin-potassium therapy for treatment of acute myocardial infarction. Exp Clin Cardiol. 2010;15(2):e20-4. 


\section{ANNEX 1}

\section{Data Source and Research}

The following terms were used in our search: "acute myocardial infarction", "diabetes mellitus" and "stress hyperglycemia" and "stress hyperglycemia in acute myocardial infarction" and (ensaio clínico aleatório controlado OU ensaio clínico controlado OU randomizado OU placebo OU terapia medicamentosa OU aleatoriamente OU julgamento ou grupos NÃO animais) and (ensaio clínico randomizado controlado e humanos) and (ensaio clínico controlado aleatório e humanos).

During the search strategy, we selected the following languages: English, Spanish, and Portuguese. However, all relevant articles were published in English, conducted in human beings, and classified as RCTs.

\section{- Definitions}

Hyperglycemia in an acute myocardial infarction event was characterized according to the definition of each researcher. Usually, these definitions included the following terms from the MedDRA terminology: "hyperglycemia after acute myocardial infarction" and "hyperglycemia and mortality in acute myocardial infarction."

\section{- Data Extraction and Quality Assessment}

Two researchers who were not involved in any of the studies selected collected the data using a pre-set table and assessed, independently, the precision of the data, solving any discrepancies through consensus after a discussion with a third researcher. The following items were extracted from the studies included: name of the first author, year of publication, study design, characteristics of the patients, sample size, duration of the intervention, type of dose control, clinical outcomes, and adverse events. If a study was published more than once, we included the most recent report. If the patients were recruited for more than one study, they were not counted twice. The Cochrane Collaboration ${ }^{1}$ tool to assess the risk of bias was used to assess the different types of bias within the studies included in our meta-analysis, and the quality of the study was assessed using the Grade ${ }^{2}$ system. Two unblinded researchers independently assessed the potential risk of bias in the RCTs using the methods described in the Cochrane Collaboration guidelines. Our co-primary outcomes were: 1) Blood glucose levels after one of the approaches had been applied, and 2) mortality for each of the approaches.

\section{- Studies Included and Excluded}

Using the Medline/PubMed, Cochrane Library and ClinicalTrials.gov databases, we identified 36 citations that used the search terms previously defined. After implementing our inclusion/exclusion criteria, we excluded 25 studies that did not present data on mortality or a comparison between a more intensive approach for the control of stress hyper-

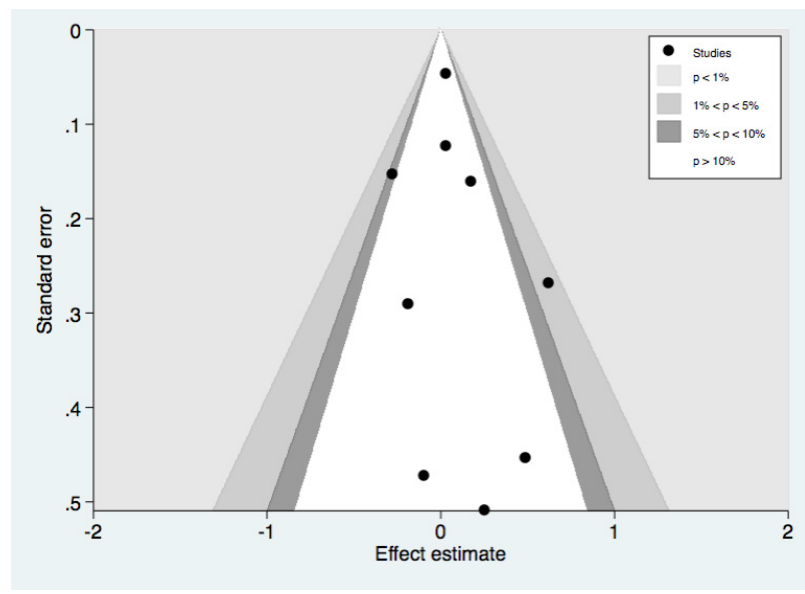

FIGURE 1

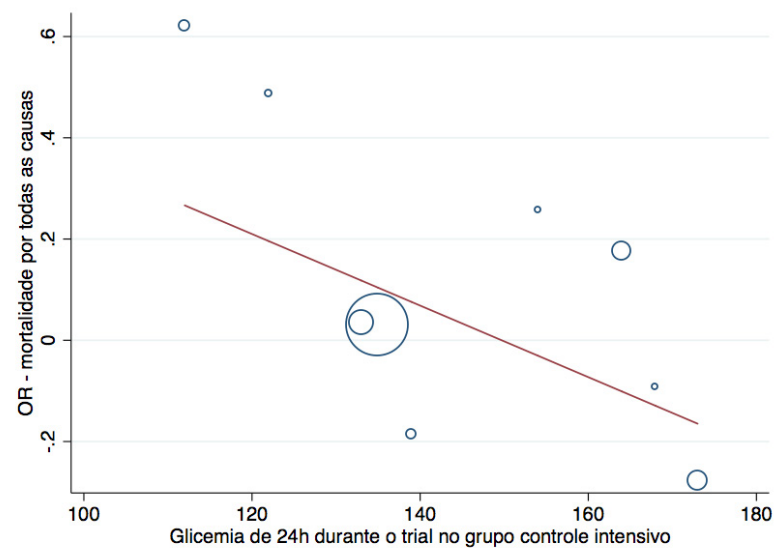

\section{FIGURE 2}

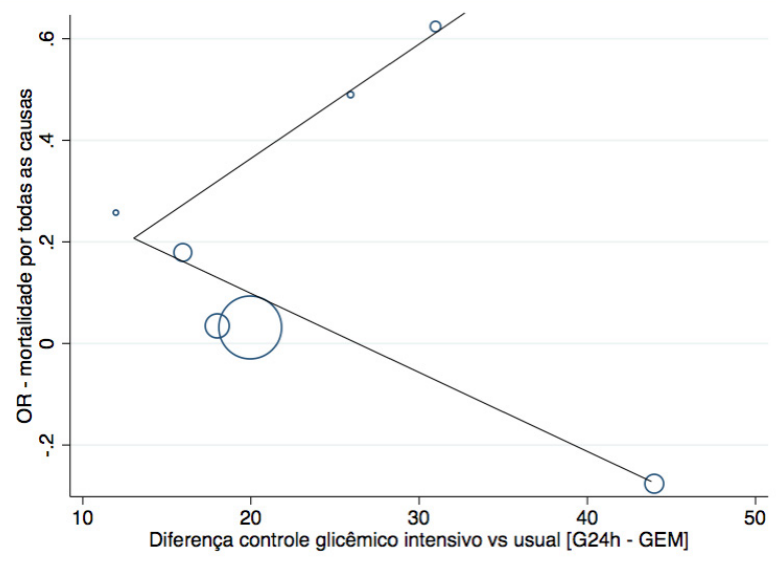

FIGURE 3 
glycemia and more conservative approaches, or that presented randomization or data analysis $(\mathrm{n}=2)$ biases, or were previous meta-analysis, which then resulted in 11 studies considered relevant for this meta-analysis.

\section{Data Handling and Analysis}

Dichotomous variables are reported as percentages, while continuous variables are reported as average \pm SD or median (interquartile range). The baseline data were obtained through weighted calculation. To identify the potential effects of the intensive strategy for blood glucose control, we calculated an overall risk ratio (RR) with meta-analyses of fixed and random effects models. Probability indexes and risk ratios were universally identical during the data analysis. We assessed the statistical heterogeneity between the trials using $\mathrm{I}^{2}$ statistics (with $\left.95 \% \mathrm{CI}\right)^{3}$, which provides a measure of the proportion of overall variation that can be attributed to heterogeneity between trials. We used risk ratios obtained through a fixed and random effects meta-analysis because they can be used as a sensitivity analysis. We used meta-regression analyses to investigate the possible sources of heterogeneity among the trials.

\section{REFERENCES}

1. Higgins JP, Altman DG. Assessing risk of bias in included studies. In: Cochrane handbook for systematic reviews of interventions. Chichester: John Wiley \& Sons; 2008. p.187-241.

2. Guyatt $G H$, Oxman $A D$, Vist GE, Kunz R, Falck-Ytter $Y$, Alonso-Coello P, et al. GRADE: an emerging consensus on rating quality of evidence and strength of recommendations. BMJ. 2008;336(7650):924-6.

3. Higgins JP, Thompson SG, Deeks J), Altman DG. Measuring inconsistency in meta-analyses. BMJ. 2003;327(7414):557-60. 